\title{
Integrating Regulatory Technology (RegTech) into the digital transformation of a bank Treasury
}

\author{
Johan von Solms ${ }^{1}$ \\ Accepted: 9 October 2020 / Published online: 27 October 2020 \\ ๑) Springer Nature Limited 2020
}

\begin{abstract}
The volume and complexity of financial regulations have increased significantly since the 2008 financial crisis. This has put increasing pressure on banks to monitor and report a range of intricate exposures to comply with new prudential requirements. Regulatory Technology (RegTech) is an emerging technology trend leveraging information technology and digital innovations that can greatly assist with a bank's regulatory management process. A consideration is that these technologies can sometimes be expensive and inefficient if deployed on an ad hoc and stand-alone basis. An option is to incorporate RegTech into the digital transformation strategy of a management function such as Treasury. Integrated adoption would mean the digital platform can be deployed to support both strategic management activities and enhanced regulatory processes within Treasury, thereby ensuring commercial and prudential objectives are aligned. RegTech can provide an invaluable tool, in a business-as-usual environment, as well as in real-life stress events, such as the recent coronavirus outbreak. This paper explores the potential of RegTech and the merit of incorporating it into a Smart Treasury department.
\end{abstract}

Keywords Regulatory Technology (RegTech) $\cdot$ Smart Treasury $\cdot$ Digital technology $\cdot$ Innovation $\cdot$ Regulations and compliance $\cdot$ Coronavirus

JEL Classification $\mathrm{G} 18 \cdot \mathrm{G} 21 \cdot \mathrm{G} 28 \cdot \mathrm{O} 32$

\section{Introduction}

The banking landscape has changed significantly over the last couple of decades and especially after the 2008 financial crisis. New regulations had an impact on many aspects of banking activity including: liquidity [1], capital management [2], profitability [3], trade finance [4], lending [5], offbalance sheet activity [6], to name but a few. Another area where there was a significant impact for many banks was in the volume and complexity of the new financial regulations and subsequent expansion of banks' compliance requirements [7-9].

The volume of regulatory reporting has increased significantly since the global financial crisis. Many regulated firms have found that reporting has become more complex and time-consuming. A large amount of reporting takes the

Johan von Solms

jvonsolms@gmail.com

1 Richmond, UK form of firms submitting structured regulatory reports, while the number of ad hoc data requests has also grown. These intermittent requests can be particularly challenging and time-consuming, since compliance with them can be very difficult to keep up to date [10].

One way to illustrate the huge growth in regulatory and compliance rules is to measure the time it would take, for example, to read the US banking-centred regulations. Based on 2017 data, it was estimated that it would take over $5700 \mathrm{~h}$ for one individual to read all the relevant regulatory materials (at a reading speed of 300 words per minute). That is almost 3 years of reading time, with only weekends off [11]. In comparison, it would take roughly $50 \mathrm{~h}$ to read the collective works of Shakespeare and one would be able to finish the Bible, cover to cover, in a slightly quicker time of around $45 \mathrm{~h}$. To view it differently, you would have been able to read through all of Shakespeare's works more than 115 times before you would be finished once with the US regulatory and compliance rules.

There are further contrasts between reading lengthy literature works and reviewing regulatory rules. Literature 
normally contains a static body of knowledge which do not require specialist training to understand and interpret the general content. Regulatory and compliance rules are dynamic in nature, since the ruleset gets updated and modified over time and requires professional training to interpret the meaning and intend. The further problem for many banks is that reading and understanding regulations, in itself, do not guarantee that the rules get implemented accurately and maintained over time.

There are a significant cost and people impact involved with interpreting, implementing and complying with new regulations. Huge et al. [12] reference the following impacts that occurred in the decade or so after the financial crisis: the cumulative cost of regulatory fines was over $\$ 300 \mathrm{bn}$; the volume of regulatory change was up by $495 \%$; and the number of employees focussing on governance, regulations and compliance was over $10 \%$ of the workforce.

Another more up-to-date example of the potential costs of regulatory breaches shows that the fines handed out by the Financial Conduct Authority (FCA) in the UK during 2019 totalled around £392mn [13].

It is crucial for financial institutions to be compliant not just from a cost-saving perspective, but for market stability reasons as well. Regulatory requirements influence the health of the economy and wider markets as a whole. They have been put in place to ensure customers are protected. Regulations also reduce the chance that central banks have to bail out banks that are not playing by the rules. In a sense, regulatory reporting is a preventive measure in that it identifies any potential issues before the effects are felt in the wider market. From a bank's perspective, being non-compliant could result in reputational damage, a loss of investor confidence and imposed sanctions, which could lead to penalties, suspension of trading and the loss of its banking licence $[14,15]$.

One recent development which could help with automating, streamlining and improving the management of regulatory requirements is called Regulatory Technology (RegTech) [16]. Arner et al. [17] define RegTech as the contraction of the terms 'regulatory' and 'technology', which describes the use of technology, particularly information technology (IT), in the context of regulatory monitoring, reporting and compliance. The automation of processes can allow for better and more efficient risk identification and regulatory compliance than that which currently exists [18]. RegTech has the ability to disrupt traditional banking and finance practices, since it can lead to a more robust and effective regulatory management process [19].

Financial regulations cover quite a wide spectrum of aspects including: reporting (e.g. capital and liquidity returns); transactional monitoring (e.g. money laundering and fraud); client identity management (e.g. Know Your Client); risk management (e.g. scenario analysis and stress testing); and others [20]. Regulations also impacts almost all business areas of the bank inter alia finance, trading, customer interfacing businesses and Treasury.

One banking function which is very involved with regulatory measurement, monitoring, compliance and reporting is a bank's Treasury department [21]. Treasury acts as a 'bank within a bank' and has a role as the guardian of the scarce balance sheet resources such as capital and liquidity. In this capacity, it works with all the business units to quantify the demand for these balance sheets resources and ensure that a sufficient supply is available [22]. Effective deployment of financial resources has a significant impact on the bank's overall health and sustainability, and therefore, meeting the regulatory requirements and reporting accurate risk numbers are crucial activities.

Many bank Treasuries are starting to adopt digital technologies such as artificial intelligence, cloud computing, robotic process automation and others to support more intelligent decision-making and enable automation of operational activities [23]. A digital Treasury in banking is becoming more of a reality, with Hawser calling it the dawn of the Super Treasurer, with artificial intelligence turning Treasury into a sophisticated analytical centre [24], and Polak et al. [25] highlighting what can be expected from an intelligent finance and Treasury function going forward.

The argument underpinning this article is that instead of duplicating RegTech implementation across the firm, it could be more optimal and efficient to integrate the regulatory management processes into the broader digital technology transformation plan of an intelligent Treasury department. The research question is: How such an integrated framework will look and the benefits it can offer Treasury? The research methodology will leverage work by Von Solms and Langerman [26] that used design science to develop a framework (i.e. artefact) called the Smart Digital Treasury Model (SDTM) to guide a Treasury's transition towards an intelligent analytical centre. The SDTM delivers improved strategic decision-making; however, the framework can potentially be expanded to also include regulatory management obligations. The contribution of this research is that if an integrated approach can be established, it can lead to cost savings and other efficiencies, but crucially also enable better alignment of strategic decision-making and regulatory management practices. This will ensure that prudential information conveyed to the regulator is the exact same information used to drive commercial strategy formulation and monitored for management actions.

The paper is structured as follows. Section 2 contains a literature review on Regulatory Technology (RegTech) and digital transformation in Treasury. Section 3 provides an overview of RegTech and its target service areas and identifies the benefits this solution can deliver. Section 4 reviews the different types of digital technologies available 
and their respective areas of application. Section 5 provides an overview of a commercial bank's Treasury department and its evolving journey towards a 'smarter' management function. Section 6 considers the evolution of regulations and the increasing regulatory obligations on Treasury. Section 7 introduces the Smart Digital Treasury Model (SDTM) approach and explains how the framework can be used to integrate RegTech into an overarching digital transformation strategy. Section 8 explores one digital technology example, namely robotic process automation, to demonstrate how digitalisation can be used to streamline data processing and support more effective regulatory reporting. Section 9 considers the advantages RegTech can offer financial organisations in unanticipated stress events-such as the market lockdown that occurred during 2020, due to the coronavirus outbreak.

\section{Literature review}

Following the 2008 financial crisis, Bloomberg estimated that the biggest global banks have been fined over USD300bn in the period up to 2017 [27]. According to Thompson Reuters in the period up to 2015, the volume of regulations has increased almost 5 times [28]. In order to manage the surge of regulations and compliance, banks have increased their workforce significantly, with knock-on effects on higher operating costs.

Citigroup estimates that the biggest banking institutions have doubled the amount of people they employ to handle conformity and regulation. This costs the banking industry $\$ 270$ bn per year and accounts for $10 \%$ of operating costs. The Spanish bank BBVA reported that on average, financial institutions have $10 \%$ to $15 \%$ of their personnel dedicated to this area [29].

Regulations have not just impacted costs and the size of the workforce, but also impacted the shape of the balance sheet. A 2015 paper by the Bank of England (BOE) [30] found that on the asset side, banks significantly increased the share of high-quality liquid assets (HQLA) to total assets to around $12 \%$, after the introduction of the individual liquidity guidance (ILG). The paper also found that adjustment in the share of HQLA to total assets was entirely offset by an equal and opposite reduction in the share of short-term intrafinancial loans, with the share of other assets remaining unaffected. On the liability side, banks increased funding from more expensive stable non-bank and non-financial corporation deposits and decreased their reliance on less stable short-term wholesale and non-domestic funding.

Regulatory changes had an effect across the board for most banks, who are struggling to manage the increased volume and complexity of the rules and governance obligations. The challenges in the way of an efficient and cost-effective regulatory reporting process are numerous, as highlighted by the Financial Service Authority (FSA) Digital Regulatory Reporting: Phase 2 Viability Assessment report [10]. The top drivers identified in this report are inter alia: too many requirements; need for additional human resources; need to introduce/update IT systems; unclear/vague requirements; redundant requirements; and too many/too frequent amendments. Digital technology solutions can address many of these constraints and is one of the main factors why the FSA established this project.

Regulatory Technology (RegTech) is an emerging application area that harness digital technology to make regulatory reporting, management and compliance easier. It offers a number of advantages including: increase in the efficiency of operational processes; reduction in risk; reduction in costs; and improvement in revenue [17]. The problem is that RegTech can sometimes be an expensive technology; at least initially, to implement [31], it does not operate efficiently in isolation and the decision where the ownership should reside within the bank can sometimes be a problematic choice [32]. One of the reasons is the way the risk management, and governance process is set up in most banks.

In the last decade or so, banks have built a governance model based on three lines of defence, in order to provide different layers of protection and oversight. The first line of defence (1LOD) is the business functions, including Treasury, that is responsible for revenue and/or risk taking. The second line of defence (2LOD) refers to the independent risk management and compliance functions that is responsible for oversight over the 1LOD and for designing and implementing the risk management framework. The third line of defence (3LOD) typically refers to the audit function that verifies all actions and activity are within the defined control framework. This creates a very strong and protective risk framework, but as pointed out by the Deloitte's 'Banking Regulatory outlook' [33], this design set-up has the downside risk that it can lead to silo-driven development of capabilities and technology.

For RegTech to operate effectively and fit seamlessly into a bank it needs to be integrated across the different lines of defence. If development is not holistically approached, there could be duplication and sub-optimal outcomes where the 1LOD will make decisions that is not always aligned with risk and reporting views generated by the 2LOD.

A department in the bank that is very involved with frontoffice activity and first-line defence, as well as regulatory measurement, monitoring and reporting, is the Treasury function. Treasury is the guardian of scarce balance sheet resources such as capital and liquidity and since the financial crisis has grown significantly in strategic importance [34].

Leveraging next-generation digital technologies can address many of the challenges Treasury face, namely streamlining data analysis; improving predictability of forecasts; creating operating efficiencies via automation; 
allowing real-time payments; and others. Furthermore, digitalisation of Treasury can deliver numerous commercial and competitive advantages as well. In order to become a Treasury of the future, it is crucial to research and outline the key drivers, benefits and strategic imperatives [35]. Polak et al. [36] also highlight the importance of having a proper and well-defined approach to guide the evolution of the Treasury function from the current state to a more automated future state, where emphasis is placed on strategic activity rather than operational processing.

To this effect, Von Solms and Langerman [26] developed a framework called the Smart Digital Treasury Model (SDTM) that provides a well-defined digital roadmap that can help establish a Smart Treasury function. This digitalisation approach can significantly improve the strategic management capabilities of a Treasury function and help a Treasurer to make an informed decision at the right time.

This intelligent Treasury mindset, which underpins the Smart Digital Treasury approach, can potentially be expanded to also include regulatory management requirements through integrating RegTech developments within the digital transformation strategy of a smart Treasury department. This paper will consider this integration, the potential economies of scale it can offer and the combined benefits of aligning the strategic and regulatory management activities of a Treasury. It is important to note that the focus is on a transnational Treasury, meaning that the logic is relevant to most jurisdictions and that the emphasis is on Treasuryspecific regulations and not the wider compliance requirements of the whole bank.

The next section will provide an overview of RegTech and how this emerging technology solution can be leveraged to resolve some of the challenges flowing from regulations.

\section{Overview of Regulatory Technology (RegTech)}

Many banks have struggled to find effective solutions to keep up with the increasing regulatory and compliance demands and additional costs. These costs can be a significant burden as identified by the European Commission in their report 'Public Consultation on the Fitness Check on Supervisory Reporting', which estimated that most firms' regulatory reporting costs are around $1 \%$ of total operating costs [37].

Regulatory Technology also called 'RegTech' has emerged as a potential lifeline to help firms ease this burden and boost their responsiveness to regulatory changes [38]. Arner, Barberis and Buckley argue that the transformative nature of this technology will only be captured by a new approach that sits at the nexus between data, digital identity and regulation [17]. This means the reconceptualisation of financial regulations through the fusing of information technology (IT) and especially digital technologies such as artificial intelligence, cloud computing, big data analytics and others to deliver effective solutions for regulatory procedures like regulatory monitoring, compliance and reporting. Johansson et al. [39] argue that RegTech is a required and necessary tool to keep up with compliance and regulatory changes.

The feasibility of deploying RegTech arose from the overlapping progress in three different areas, namely increased financial and prudential expertise, technology improvements and higher volume of regulations [12]. These different developments with RegTech residing at the heart is depicted in Fig. 1.

It is also important to understand how RegTech relates to financial technology (FinTech) developments. FinTech is the use of technology to create new financial solutions [40]. There is an argument that RegTech is a subsegment of FinTech that deals with regulations [12, 41]. In contrast, other authors such as Arner et al. [17] and Johansen [39] believe that although RegTech has its roots in FinTech it should be considered as an independent sector, because it provides services for different groups not only the financial sector and has other recipients. The argument for separating the two industries is that FinTechs are changing the financial industry and becoming a challenger to traditional banking, while RegTech are being developed to assist all financial institutions (old or new) to deal with their regulatory obligations [39].

RegTech has the ability to standardise, automate and speed up a lot of manual activities, which can make the regulatory process more robust and economical. RegTech solutions offer enhanced characteristics [42], inter alia:

- Agility cluttered and interlinked data sets can be decoupled and organised through using more intelligent technologies;

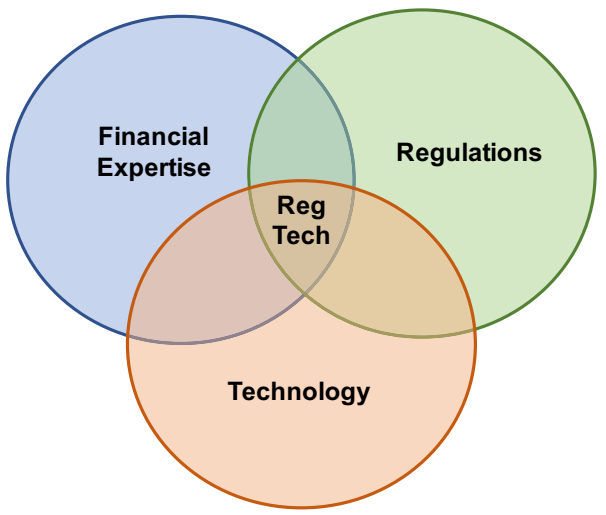

Fig. 1 RegTech resides in the overlap of financial expertise; regulations and technology 
- Speed reports can be configured and generated in a quicker turnaround time;

- Integration integrated approaches allow for shorter timeframes to generate operational solutions get them up and running; and

- Analytics advanced analytical tools can intelligently process existing big data sets and unlock true value, e.g. improved insights and sourcing the same data for multiple purposes.

RegTech is an exciting new technology development that is showing a lot of promise to make it easier and simpler for financial institutions to comply with ever-changing regulations, while reducing manual processes that cause errors and impact time and headcount. The next section looks at the main drivers influencing RegTech deployment and the type of service areas the technology is currently being applied to.

\section{Drivers of RegTech developments and key regulatory service areas}

Prior to the 2008 financial crisis, regulatory rules were significantly less onerous in terms of scope and complexity and were often managed by a small group of people on a non-dedicated and often quasi-manual basis. An example is the Sterling Stock Liquidity Regime, which enforced liquidity rules for the major sterling clearing banks in the UK. It required banks to hold a stock of Bank of England eligible assets to meet wholesale sterling outflows over the next 5 days and cover $5 \%$ of maturing retail deposits, withdrawable over the same period [30], often managed by the firm's Money Market Funding desk. This is in marked contrast with the far more complex new liquidity standards introduced by the BASEL III Accord, like the liquidity coverage ratio (LCR) that measures all contingent outflows and liquidity stresses for on- and off-balance sheet exposures over a 30-day horizon. The point is that it is becoming far more difficult to measure and monitor complex prudential metrics-for example, frequently refreshed granular cashflow forecasting-without the use of dedicated IT systems and the involvement and coordination of a wider stakeholder group.

Reviewing the academic literature, there are a number of drivers which are influencing the progress in RegTech. These drivers are described in more detail below:

1. Significant amount of complex regulatory change Thomson Reuters [28] highlights that the volume of rules have increased manifold over the last couple of years making it difficult for financial firms to review and keep track of all the prudential changes.

2. Ineffective legacy design set-up the FSA report on digital reporting [10] found that many banks have fragmented and siloed regulatory and compliance functions and IT systems, often requiring a lot of manual intervention.

3. Enabling technology certain digital technologies, such as artificial intelligence, have been around for a while, but due to recent growth in processing power and distributed computing, they have become a more feasible option $[24,43]$.

4. Range of benefits - 'Disrupting Finance: FinTech and Strategy in the 21st Century' edited by Lynn, Mooney, Rosati and Cummins [19] identifies a number of benefits for organisations including:

(a) Increased revenue $\mathrm{RegTech}$ automation can increase competitiveness while increasing customer satisfaction and retention, through faster onboarding and completion of, for example, Know Your Client (KYC) and anti-money laundering (AML) requirements.

(b) Reduced costs can deliver streamlined and automated processes that reduces the number of people needed to manipulate data manually and check for errors, lowering the overall compliance cost.

(c) Efficiency and productivity gains RegTech flexibility enable banks to adjust to regulatory volume and changes more efficiently and produce reports more frequently. They also allow personnel to focus on value added services such as strategic activities.

(d) Reduced risk/improved governance when banks can comply with regulations and the myriad of other compliance requirements more easily, they are less likely to suffer reputational damage, penalties and fines from compliance missteps.

5. Supervisory improvements many regulators are also evaluating the benefits that RegTech can offer from a supervisory perspective, as described by Podder et al. [16]. One example is that the large amount of regulatory reports submitted by banks to the regulator needs to be reviewed and assessed, which often entails a cumbersome and slow process for the regulator.

6. Wider digital adoption integration of RegTech within a firm-wide digital technology strategy can result in a more robust bank and deliver true economies of scale [44].

One of the big considerations when evaluating where and how to deploy regulatory-specific technology is that regulations are very broad in terms of scope and requirements and can differ between regulators. Regulations cover all aspects of the bank's activity and jurisdictional footprint. It is therefore crucial to try and understand and explore the different focus or service areas of regulations to establish what type 
of digital technology would be most appropriate to address a specific problem. In the 2020 Deloitte report 'RegTech Universe 2020' authored by Huge et al. [20], five main service areas of RegTech developments are identified, as well as the companies operating in this Regulatory Technology space (which for interest totals 378 RegTech companies). The main targeted services areas include:

\section{Service area 1: regulatory reporting}

Regulatory reporting is the mandatory submission of data by banking and financial services firms to a regulator, to establish transparency into their activity and ensure banks meet all the prescribed constraints. These data have to be periodically submitted to the relevant regulatory authority, normally monthly, quarterly and annually. However, for certain risks like intraday liquidity it might even be daily. Reporting in itself can cover a wide range of different financial disciplines including: financial reporting (e.g. FINREP); prudential reporting (e.g. BASEL III); and transactional reporting (e.g. MiFID II).

\section{Service area 2: compliance}

Regulatory compliance entails meeting prudential rules as prescribed through specifications, policies, standards or laws and the steps taken to comply with all the relevant directives. Due to the increasing number of regulations and need for operational transparency, organisations are increasingly adopting the use of consolidated and harmonised sets of compliance controls. This approach is used to ensure that all necessary governance requirements can be met without the unnecessary duplication of effort and activity.

\section{Service area 3: transaction monitoring}

Transaction monitoring refers to the monitoring of customer transactions, including assessing historical and current customer information and interactions to provide a complete picture of customer activity. This can include transfers, deposits and withdrawals. It is a key mitigant against antimoney laundering (AML). As a recent example of rule changes, in January 2020 amendments to the UK Government's Money Laundering Regulations came into force. This updated the UK's AML regime to incorporate international standards set by the Financial Action Task Force (FATF) and to transpose the EU's 5th Money Laundering Directive [45].

\section{Service area 4: identity management and control}

Know Your Customer (KYC) is a standard in the financial industry that ensures investment advisors and banks have detailed information about their clients' risk tolerance, investment knowledge and financial activity. KYC protects both clients and financial institutions and typically involves requirements and policies such as risk management, customer acceptance policies and transaction monitoring.

\section{Service area 5: risk management}

Risk management includes the quantitative management of different risks across the firm and included scenario analysis, exposure computation and reporting of the exposures.

The management of these regulatory requirements puts ever-increasing pressure on banks in terms of complexity, scope and frequency. Emerging digital technologies can play a key part to help with this increasing onerous regulatory management activity and demands.

The next section looks at the different available digital technologies and in what regulatory service areas they can be utilised, as part of RegTech application.

\section{Overview of digital technology utilisation in RegTech}

Digital technology solutions, for example artificial intelligence, have been around for many years, but it is only recently with the expansion in computing power and distributed processing that digital technology has become more viable from a cost perspective and practical to combine with data analytics. Below is a short overview of some of the emerging digital technologies that can be leveraged to meet the increasing demands of the regulatory process $[16,46]$ :

- Big data (BD) analytics this can be leveraged to obtain better insights from structured and unstructured data and support programmable reporting. This technology can help learn more about customer behaviour along with their connections. Many regulatory issues such as money laundering and fraud tend to emerge from behaviours or transactions that is difficult to discover through traditional risk and control frameworks.

- Natural language processing (NPL) this technology can support onerous regulatory compliance tasks that include scanning for revised or new regulations and modified risk reporting. These algorithms can be automated to perform these functions continuously, share the impact with compliance process owners and also identify important decision-making drivers.

- Robotic process automation (RPA) RPA can deliver productivity and efficiency gains by automating non-value additive manual activities like data extraction, formatting and reconciliation tasks. When the risk reporting process is automated, it becomes easier to handle increased vol- 
ume, higher granularity and various regulations across different jurisdictions.

- Distributed Ledger Technology (DLT) digitalisation of diverse RegTech-related processes can minimise the dependency on back-office personnel and departments. By replacing such traditional procedures with digital verifiable workflows, compliance and regulatory practices would be enhanced.

- Artificial intelligence (AI) AI can assist with delivering a smarter and more efficient onboarding process of new clients, identify weaknesses in existing risk and control frameworks and help guide intelligent allocation of financial resources.

- Cloud computing $(C C)$ historically to integrate fragmented data systems in order to produce a real-time standardised view of risk information would have required a significant upfront IT investment and long lead time. CC can solve a number of these data and processing challenges more quickly and effectively. A cloud platform allows businesses to scale as requirements change and it becomes easier to incorporate other data methodologies and analytics, such as machine learning and big data analytics.

- Machine learning $(M L)$ can help with the back-testing of computational models and improve the predictability of the forecasting of cashflows.

- Application programming interface (API) the plug and play features of APIs can deliver better integration of fragmented activities and enable automated reporting to regulators.
Figure 2 illustrates potential application of these digital technologies across the different regulatory service areas, identified in Sect. 3, that can enable RegTech solutions. The application and combination of technologies are not definitive and can take many forms. As an example in the case of regulatory reporting, natural language processing can help interpret the rules and identify updates to the ruleset; robotic process automation can automate the production of the necessary reports; distributed ledger technology can help ensure the report production is verified and checked throughout the process; and lastly, application programming interface can enable the straight-through submission of the required reports to the regulator. These utilisation of digital technologies in isolation or in combination can transform the compliance and regulatory process, across the regulatory service areas by leveraging advanced analytics, intelligent algorithms and distributed processing power [46].

Going beyond its role in helping banks to comply and enforce regulation, RegTech can also deliver significant benefits for the regulator [41]. The digital checks and balances RegTech can offer the regulator are similar to fitting highperformance brakes on a racing car. Counter-intuitively, the brakes are vital to the driver's ability to go fast-without a trusted mechanism to reduce speed, drivers would all have to drive slowly. Similarly, when it comes to observing regulations, RegTech can provide the confidence the markets need for commerce to move faster and to more rapidly adapt to disruption.

A core department within a bank that is very involved with the management and implementation of prudential regulations and compliance is the Treasury department. Many Treasury departments have started on a digital

\begin{tabular}{|c|c|c|c|c|c|}
\hline & $\begin{array}{l}\text { Regulatory } \\
\text { Reporting }\end{array}$ & Compliance & $\begin{array}{c}\text { Transaction } \\
\text { Monitoring }\end{array}$ & $\begin{array}{c}\text { Identity } \\
\text { Management }\end{array}$ & $\begin{array}{c}\text { Risk } \\
\text { Management }\end{array}$ \\
\hline Big Data Analytics & & & 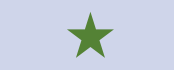 & t & 九 \\
\hline $\begin{array}{l}\text { Natural Language } \\
\text { Processing }\end{array}$ & $\hat{x}$ & & & & \\
\hline $\begin{array}{l}\text { Robotic Process } \\
\text { Automation }\end{array}$ & t & & $\star$ & & \\
\hline $\begin{array}{l}\text { Distributed Ledger } \\
\text { Technology }\end{array}$ & t & t & & & \\
\hline Artificial Intelligence & & & t & 사 & 大 \\
\hline Cloud Computing & & $\star$ & & 太 & \\
\hline Machine Learning & & 九 & & & 九 \\
\hline $\begin{array}{l}\text { Application } \\
\text { Programming Interface }\end{array}$ & $\star$ & 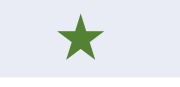 & & & \\
\hline
\end{tabular}

Fig. 2 Application of RegTech across regulatory service areas 
transformation journey [23] to support their increased strategic management mandate [34]. The next section will provide a brief overview of the changes in a bank's Treasury and how some departments are starting to transition towards becoming smarter management functions.

\section{Treasury overview}

A bank's Treasury department plays a crucial role in a bank, as the guardian of the balance sheet and the manager of the firm's scarce financial resources such as capital and liquidity [23]. It is such an important area in a financial organisation that Hewlett [47] argues that a bank's Treasury should be positioned at the centre of strategic planning.

Treasury functions have existed in some form for centuries, but its role have changed significantly in the span of the last 30-40 years. Treasuries emerged in the 1980s as a distinct function from the bank's finance department [21]. At that time, Treasury activities were primarily centred around cash and working capital management. This focus started to change in the 1990s as a consequence of corporate restructuring and the way organisations used technology and information [48].

In the first decade of the twenty-first century, the Treasury department continued to evolve further to meet the expanding need of the bank. During this period, a number of authors researched the increasing importance of this management function highlighting various development aspects and focus areas within a Treasury. Maphiri [49] identified the important role of Treasury in cash management and the stability of the financial organisation. Van Rooyen and Reitsma [50] considered the future effect of E-Business on Treasury and risk management systems. Helliar and Dunne [51] studied the Control Mechanisms and processes in place (or lack of effective corporate governance) in Treasury departments, after the collapse of companies such as Barings and Enron. San-Jose et al. [52] explored the growing influence of information technology Systems on finance and Treasury departments performance and identified the benefits, in terms of cost savings and improved decision-making. Polak [53] argued the need for centralising a bank Treasury function in the globalised world.

In 2010, a comprehensive overview of Treasury practices was provided in 'Treasury Management: A Practitioners Guide' authored by Bragg [54]. It reaffirmed the importance of a Modern Treasury function and described all the main activities required in a 'best practice' Treasury.

The world of banking in general and Treasury in specific, however, changed dramatically after the 2008 financial crisis. The reason was due to banking supervisors issuing a range of new regulatory and compliance regulations to prevent another financial disaster. This required increased number of Treasury experts and specialised knowledge to implement the complex prudential rules and restructure the bank's balance sheet to conform to the new constraints.

This forced the role and responsibility of a Treasury to undergo another major change in terms of scope and strategic importance, moving from a transactional manager to a balance sheet custodian [55]. Given the role of Treasury as the 'bank within the bank', as well as its impact and influence on the wider financial market stability [22], many treasuries are exploring the utilisation of new technology to help them transition to a smarter analytical centre that can make more informed decisions in real time.

The concept of a smart Treasury function and the benefits of leveraging digital technologies have been identified by a number of authors in recent times. Hawser [24] argues that it is the dawn of the 'Super Treasurer' and that artificial intelligence can turn the Treasury function into a sophisticated analytical centre, while Meall [56] highlights the importance of digital technology as a Treasury survival strategy.

The core argument of this paper is that there is merit in integrating digital technology developments in management areas such as Treasury to deliver improved strategic management practices as well as enhanced regulatory processes. This alignment will ensure consistent decision-making between the bank's strategy and what is reported to the regulator or the rules being complied to. This integration idea will be explored in more detail in the next sections, by considering the impact of regulations on Treasury activities and then describing an approach how RegTech can be combined with the wider digital technology developments in Treasury.

\section{Banking regulations and Treasury}

Bank regulations and rules have evolved significantly over the last couple of decades and especially since the 2008 financial crisis. Various new rulesets were published by regulators inter alia: Dodd-Frank Wall Street Reform and Consumer Act (Dodd-Frank), Sarbanes-Oxley Act (SOX), Markets in Financial Instruments Directive (MiFID II), Basel accords (Basel III) and others. The Basel regulations are global standards that are set by the Basel Committee on Banking Supervision (BCBS) and are regulatory rules that set out a minimum requirement for aspects such as bank capital adequacy, stress testing, market risk, leverage, liquidity risk and other types of risks impacting a bank's balance sheet viability. The third version of the Basel Accords, namely Basel III, was developed in response to the deficiencies in the financial regulation revealed by the financial crisis of 2008. The updated and revised standards were intended to strengthen bank capital requirements, increase bank liquidity and decrease balance sheet leverage [57]. 
Basel III expanded the Basel II rules in terms of measuring credit risk and the need for additional capital adequacy buffers, but it also introduced a range of new regulations. These included new metrics for measuring and monitoring inter alia: liquidity risk [58], i.e. liquidity coverage ratio (LCR) and net stable funding ratio (NSFR) and enforcing specific leverage limitations on the size of the balance sheet [59].

These expanded rules created a lot of new challenges for treasuries and other banking functions to measure, monitor and manage the exposures, but especially to report these prudential numbers to the regulator. In order to supervise the implementation and especially the adherence to these new rules, central banks required that commercial banks on a frequent and granular basis report their capital, liquidity and leverage and other exposures.

The number and complexity of prudential reports have ballooned significantly over the last couple of years. As an example of this extend, looking at the Bank of England's webpage [60], it highlights the range of regulatory reports required. Indicatively the number of reports covering aspects such as the balance sheet composition, capital, liquidity, market risk, leverage, interest rate risk and others are over 50 in number. And that exclude requirements from other regulators like the European Central Bank (ECB) and Federal Reserve (FED) applicable to global banks which operate in multiple jurisdictions.

In addition to daily risk management activities, the reporting of prudential numbers is a significant obligation for many areas in the bank including the Treasury function. Below is a couple of examples to illustrate the range of Treasury responsibilities and the additional complexity in light of the required regulations.

\section{Treasury risk management and reporting challenges}

\section{Computing capital demand and supply}

The capital adequacy requirement and computation of riskweighted assets (RWA) in banks have changed significantly over the last couple of years, with the evolution of Basel I through Basel III. Treasury has to interact with all frontline businesses units that have RWA exposures, generated through taking credit risk, market risk, operational risk, counterparty risk, etc. in order to construct a holistic picture of the total bank-wide RWA demand. It also needs to work closely with the finance department to model forecasted future impacts of RWAs and profitability to determine whether the bank will have sufficient equity and other capital sources to meet its minimum capital adequacy and additional capital buffer requirements. It is a very difficult and timeconsuming process to consolidate fluctuating RWA demand, compute available capital supply and especially model the potential range of future outcomes. Given the fragmentation of different product systems, the process often involves manual interventions, which can be prone to errors and is difficult to duplicate for different what-if/back-testing scenario analyses.

\section{Managing the liquidity coverage ratio (LCR) and net stable funding ratio (NSFR)}

Prior to the financial crisis, there was no comprehensive global standard for liquidity management in place. This changed through the introduction of the LCR and NSFR regulations. The LCR requires that a bank holds at least a $100 \%$ of high-quality liquid assets (HQLA) against contingent liquidity outflows for both on-balance sheet and off-balance sheet exposures over a 30-day horizon. In contrast, the NSFR assesses the risk over a 1-year horizon and requires that a bank has enough stable funding sources to meet all required funding outflows over this period. Both of these measures are complicated to compute and report given the need to first capture all notional cashflows over the 30 day or 1-year horizon and then apply the correct prudentially prescribed stress outflow weights. What makes this activity even more demanding is that regulators often expect banks to demonstrate the ability to produce these liquidity reports daily.

\section{Structural product and equity hedging}

A large portion of a bank's funding base originates from non-maturing deposits, which means the products have no definitive contractual maturity date, e.g. current accounts and common equity. These types of funding products share a couple of characteristics that can have a significant impact on a bank's net interest margin (NIM) stability. The first is that although this funding can contractually leave the bank within a day (either through client withdrawal or a credit loss) in practice they remain stable for long periods of time. Secondly, the interest rate paid on these funds is close to zero, thereby equating to a long-term $0 \%$ fixed rate loan for the bank. In turn, these funds are normally lent out to loan customers, on which the bank receives a floating interest rate. This net interest rate position can create a significant fixed or floating interest rate exposure in the banking book. This can impact the bank's NIM stability, meaning that if market rates go up the bank's income increases, but if the market rates fall income decreases. Therefore, most banks execute a structural swap hedge to mitigate this exposure and therefore stabilise the net interest margin. Since this hedging activity can significantly influence the bank's income (i.e. future profitability), regulators are very interested in the underlying assumptions and the models that underpin these decisions. 


\section{Consequence of ineffective regulatory processes}

These examples illustrate only a couple of the challenges that bank treasuries face on a daily basis in managing and reporting bank risk positions. They need to measure and monitor these complicated risks dynamically, but also report the exposures to the regulators timeously and with the appropriate governance and control. Incorrect reporting, bad systems or unexplained decisions can have significant impact on the bank's reputation and can often lead to penalties and fines.

As an illustration, at the end of 2019 the Prudential Regulatory Authority (PRA) imposed a combined financial penalty on Citigroup Global Markets Limited (CGML), Citibank N.A. London branch (CBNA London) and Citibank Europe Plc UK branch (CEP UK) (together, Citi) of $£ 43.9$ million for failings in relation to their internal controls and governance arrangements underpinning compliance with PRA regulatory reporting requirements. Between 19 June 2014 and 31 December 2018, or parts thereof, the firm's UK regulatory reporting framework was not designed, implemented or operating effectively. This led to them failing to submit complete and accurate regulatory returns to the PRA [61]. In particular, the following items were highlighted:

- Citi failed to ensure that systems and controls supporting its UK regulatory reporting framework were designed, implemented and operating effectively;

- Citi failed to allocate adequate human resources to ensure that CGML's liquidity returns were complete and accurate;

- Citi's documentation of multiple aspects of its UK regulatory reporting control framework was inadequate given its size, complexity and systemic importance;

- CGML's approach to technical interpretations of reporting requirements was insufficiently robust given the complexity of those decisions and the impact they could have on the accuracy of the returns; and

- Citi's oversight and governance in relation to regulatory reporting fell significantly below the standards expected of a systemically important institution.

\section{Integrating RegTech into a Treasury's digital transformation}

Considering the Citi case [61] and other similar examples, there appears to be a number of common themes and challenges to successfully managing regulatory demands including: fragmented data systems; manual time-consuming data manipulation/less time for strategic focus; real-time reporting demand; interpretation of complex rules and regulations; effective governance and control around the process; and updating new regulations $[10,19,62]$.
Modern regulatory challenges require modern tools and these need to be as dynamic as the organisations they support. RegTech systems can harness global data sets in a way that offers new and timely insight into regulatory processes, automating compliance and risk management tasks by pooling and aggregating data from a range of sources. Often these data are too complex, too varied and too expensive, to review manually.

However, to make these technologies an intrinsic part of the bank can be costly and time-consuming, and not just during the implementation phase, but as part of the ongoing maintenance. This applies to the cost of both acquiring and deploying an automated computer-based system and the ongoing operational costs. It is therefore imperative that financial institutions have a sound understanding of the regulations they are required to follow, the processes that their business needs to put in place and the most efficient method of implementing and enforcing these processes.

Another consideration is that RegTech cannot effectively be implemented and used on a stand-alone basis. It needs to form part of an integrated deployment of digital technology in order to achieve true economies of scale. One solution is to incorporate RegTech into the digital transformation strategy of Treasury. The result would be that digital solutions could be leveraged to support both enhanced strategic management activity and better quality regulatory reporting.

Von Solms and Langerman [26] developed a framework called a Smart Digital Treasury Model (SDTM) that provides a well-defined digital transformation plan for a Treasury to assess its digital maturity level and guide the effective adoption of digital technologies. This framework can be expanded to include some of the regulatory management demands and therefore deliver an integrated and effective RegTech solution as part of the SDTM framework. The next section will introduce the framework and explore how it can be expanded to include the Regulatory Technology angle.

\section{Smart Digital Treasury Model (SDTM)}

\section{Overview of the SDTM}

Given the changing nature of Treasury and its increasing strategic management mandate, it is crucial to follow a welldefined framework to determine the current digital maturity and enable the transitioning to a more advanced digital user. The Smart Digital Treasury Model (SDTM) was developed for this purpose, to support and guide the evolution towards a next-generation smart Treasury [26]. Figure 3 provides more insight into the underlying steps/building blocks of the SDTM.

The model comprises of 4 steps/building blocks, i.e. 
Fig. 3 Smart Digital Treasury

Model
Towards a next generation smart Treasury

SMART DIGITAL TREASURY MODEL

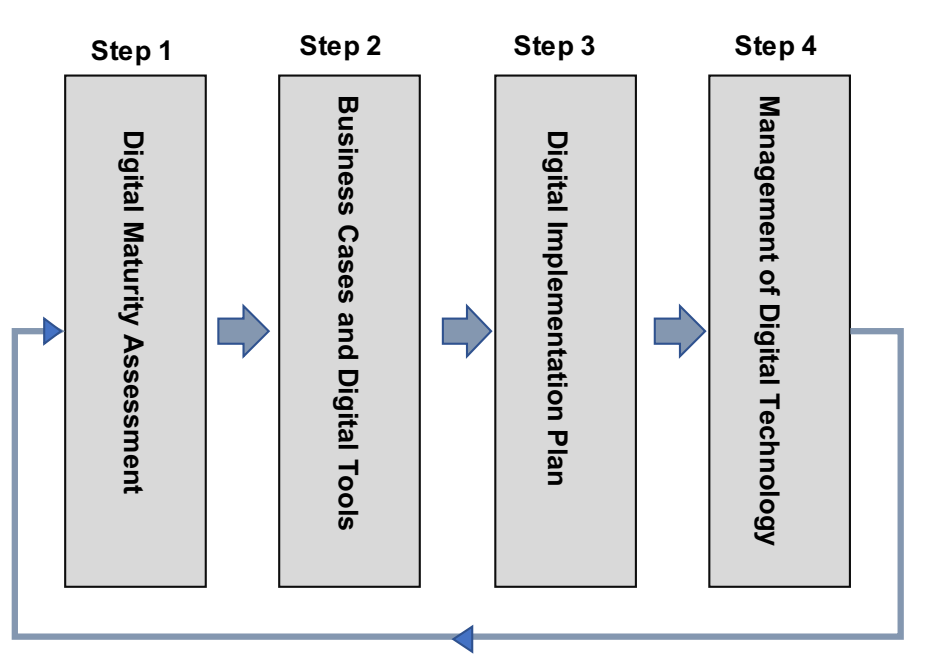

- Step 1: Digital maturity assessment measures the digital maturity of a Treasury against a specific set of criteria and scores the digitalisation level/readiness on a scale from none to expert, across key digital dimensions. It then identifies and describes digital use cases for core Treasury activities and orders these for further digitalisation development.

- Step 2: Business case development and digital tool evaluation digital use cases are mapped into the most appropriate digital technologies. These are then build out into more detailed business cases and prioritised based on defined requirements including performance hurdles like return on investment ( $\mathrm{ROI})$. This is to ensure that the implementation will deliver the expected benefits and that Treasury successfully transition to a more digitally mature state.

- Step 3: Digital road map of technology implementation this step articulates the implementation plan and development method (e.g. DevOps, Agile Lean) to roll out the selected new digital technology.

- Step 4: Management of new digital technology and risks managing the changes and increased threats and risks arising from digitalisation in Treasury is an important consideration. Digitalisation therefore requires a dedicated approach to identify and mitigate these potential risks.

\section{Expanding the SDTM to include regulatory processes}

The SDTM which was originally designed to enhance strategic management activities within a Treasury department can be expanded to accommodate certain regulatory activities and services areas as well. This logic is illustrated in Figs. 4 and 5 and described in more detail below.

The digital maturity assessment of a Treasury department including all of its activities [63] is a crucial step to measure the existing level of digital technology utilisation and identify any gaps (Step 1 of the SDTM). This digital assessment and the construction of digital use cases of Treasury management activities can be expanded to also cover key regulatory activities, for example regulatory reporting. Figure 4 shows how the spectrum of Treasury management activities and regulatory service areas can be combined to establish a comprehensive digital assessment picture. The rationale is that there is a large amount of communality and overlap in the way that underlying data are extracted and processed. Using an integrated approach will ensure future consistency between reporting views and strategic management views.

The digital use cases covering the comprehensive set of Treasury activities can then be mapped into the most appropriate digital technologies (Step 2 of STDM see Fig. 4). This will ensure that RegTech is not developed on a stand-alone basis or that there is duplication of digital solutions across Treasury. After identifying the most effective digital technology, the digital uses cases are then build out into detailed business cases and prioritised based on specific metrics such as the benefit achieved and the implementation effort required. The use of digital technology for regulatory purposes (RegTech) will also strengthen the collective business case justification to obtain senior management support for implementing these types of innovations within Treasury. Commercial metrics such as return on investment (ROI) will be significantly enhanced if digital technology solutions 


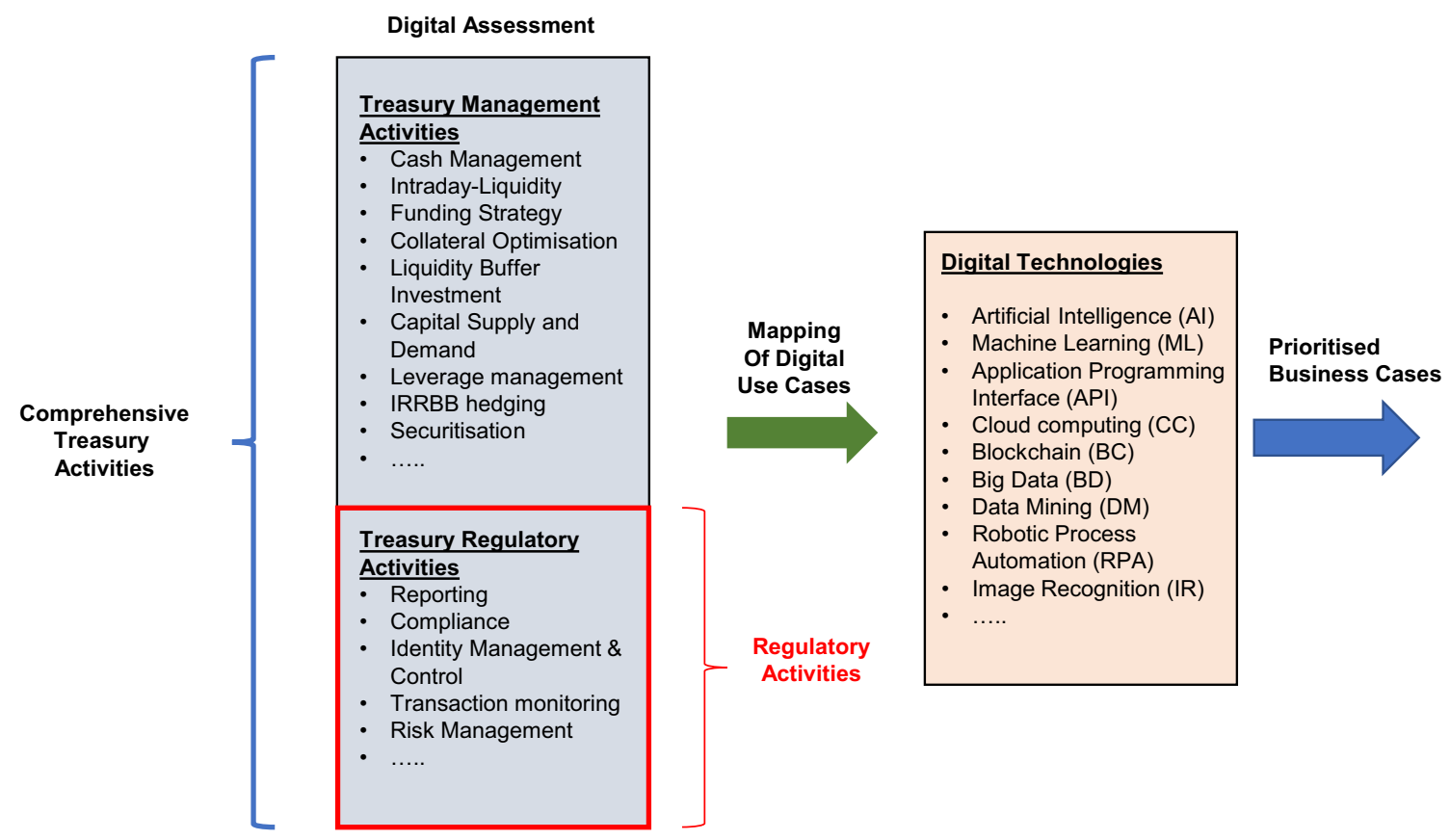

Fig. 4 Combining management and regulatory tasks into a holistic framework

Fig. 5 Integrated IT implementation
Underlying Systems

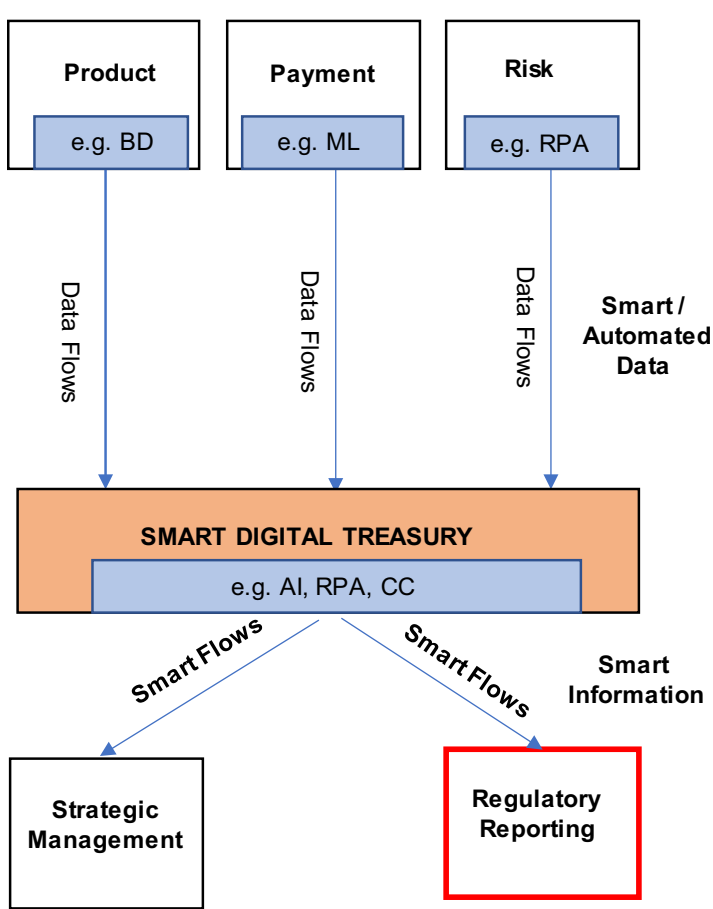

Digital

Technologies 
are leveraged for both management and regulatory-driven purposes.

Once the most feasible business cases have been identified and prioritised, the next step is to consider implementation. As an illustration of a potential implementation design and set-up, Fig. 5 depicts a high-level system architecture (Step 3 of SDTM). Selected digital technology solutions can be embedded into core underlying bank systems, for example: big data (BD) analytics applied to customer product systems will help to better understand customer behaviour; machine learning (ML) embedded within the payment systems can improve the intraday liquidity risk management; and robotic process automation (RPA) can be harnessed to automate data extraction from the risk management systems (see the next section for more detail). This form of digital adoption will allow for automated and smarter information to flow into Treasury and its Treasury management systems to enable a smarter management function. Furthermore, Treasury can augment this smart information with additional digital analytics, e.g. artificial intelligence, to drive subjective-driven strategic activities such as optimal allocation of financial resources such as capital and liquidity.

The integration of RegTech into the Treasury IT infrastructure will establish a Smarter Treasury function that can support more effective strategic management decisions, as well as produce automated and streamlined regulatory reporting. As Fig. 5 shows, such an integrated set-up will ensure decision-making and reporting are aligned and supported by intelligent information.

By reducing the manual and time-consuming operational overhead involved with reporting activities, the Treasury's human resource requirement will also reduce. But rather than become obsolete these personnel can then be more efficiently be deployed to focus on subjective and strategic management activities, such as optimisation of the balance sheet, and therefore deliver real bottom-line value for the bank. They can also assist with the management of the additional risks and threats that can arise from the use of digital technology such cyber security; ensuring models are fair and unbiased; and explainability of results (Step 4 of SDTM).

The next section will focus in more detail one specific digital technology, namely robotic process automation (RPA), and how it can deliver improvements to the Treasury's management and regulatory reporting process through enabling automation.

\section{Integration of RegTech in a Smart Treasury through using robotic process automation (RPA)}

One of the most time-consuming operational activities in a Treasury is the extraction, formatting and reconciliation of data from various different source systems for management purposes and to feed the production of regulatory reports. This is often a complex and manual-intensive task since there is a dependency on diverse range of legacy systems (i.e. product, risk management, accounting, payment and trading systems) which is often not designed for the modern regulatory and management requirements. Many Treasury personnel may therefore be involved with the process of obtaining and constructing a consistent data set-which often requires minimal levels of subjective judgement or intelligent engagement. This type of process is inefficient and open to a number of risks and weaknesses, e.g. easy to make errors; difficult to duplicate and repeat on more a frequent basis; and problematic to update if regulations change (i.e. data rules are hard-coded). It can also lead to regulatory data being inconsistent with management information, i.e. strategic decisions are made that is misaligned with regulatory reports.

An innovative technology solution like RPA can significantly assist in streamlining and automating the reporting process [64]. RPA technology works very well in an environment which has the following characteristics: high level of manual calculation; electronic start and end points; high error rates; data intensive; and repetitive in nature. Figure 6 shows the common steps involved from data input to producing a report. The first 2 or 3 steps in the process (i.e. data input, data output and reconciliation) share a lot of the above characteristics and tend to require minimal levels of subjective judgement.

Ernst and Young estimates that there can be significant reduction in full-time equivalent (FTE) personnel, if RPA technology is implemented to assist with data extraction, formatting and checking of correctness [64]. These human resources can then be deployed more optimally to focus on strategic and subject activities like assessing the underlying business and regulatory rules and interpreting the management information output of the various reports. The benefits of deploying RPA for Treasury regulatory activity include: automated systems can operate 24/7; improve granularity and frequency of updates; reduce FTE required; minimise error rates; integrate relatively well within existing IT landscape; can be trained by humans; and lead to redeployment of Treasury staff to more strategic functions.

RPA is only one example of how a specific digital technology can help to automate operational activities within a 
Fig. 6 Increased subjective judgement involved with a reporting task

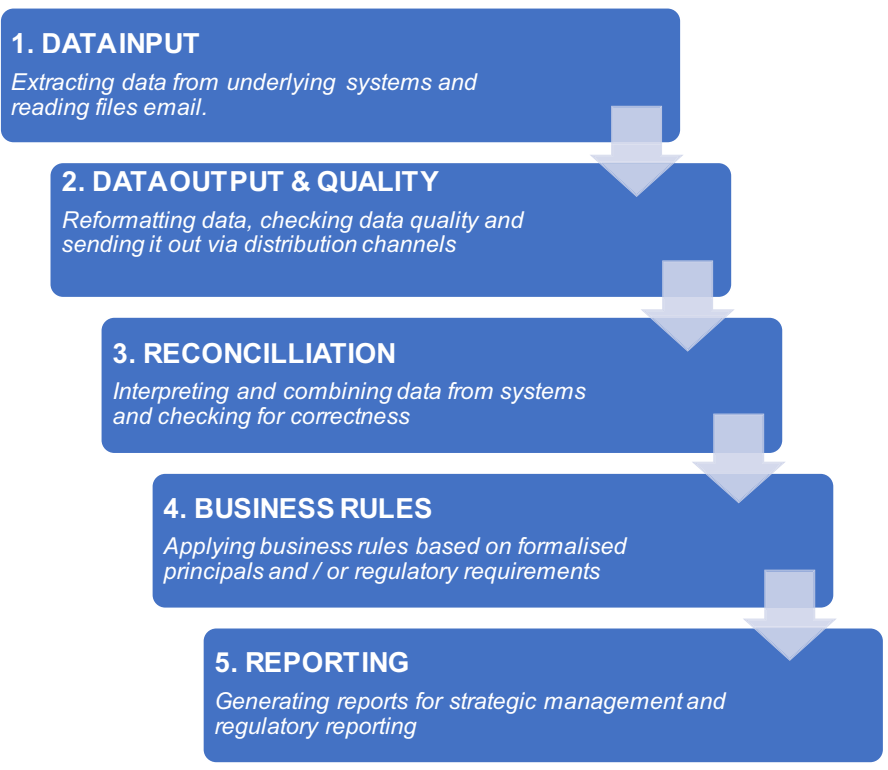

of money market activity and debt capital markets issuance opportunities and reduction in intrabank lending activity.

In order to reduce the impact on the financial markets, many central banks provided a variety of regulatory relieve packages. This ranges from injecting liquidity into the markets to allowing regulatory dispensations, e.g. lowering the liquidity coverage ratio (LCR) requirement and/or allowing banks to dip into their additional capital buffers. As illustration, the South African Reserve Bank (SARB) lowered the LCR requirement to $80 \%$ for the duration of the stress [65] and the Bank of England (BOE) allowed banks to offset increases in market risk capital, due to higher volatility in the value at risk calculation through a commensurate reduction in risks-not-in-VAR (RNIV) capital requirements [66].

The issue is that although commercial banks might be allowed to temporarily dip into their liquidity and capital buffers, the expectation is that after a crisis they will revert back to the normal prescribed levels. In the absence of RegTech infrastructure, this can become a very difficult process to measure, monitor, manage and ensure future compliance.

Digital technologies underpinning RegTech can play a key role in assessing the fluctuating regulatory metrics and crucially ensure the freed-up capital and liquidity are optimal deployed across the bank, i.e. diverted to areas where it is needed the most. For example, big data analytics can be leveraged to analyse how customer behaviour will change under the unique stress event, e.g. how many clients will take up the loan repayment holiday offer and therefore impact the bank's profitability; robotic process automation can allow for quicker generation of regulatory reports to assess the impact of liquidity and capital changes on key prudential metrics; and artificial intelligence can identify weaknesses in funding and liquidity available to banks through a slowdown 
existing risk and control frameworks and help guide intelligent reallocation of additional capital and liquidity resources to affected areas.

These are only a couple examples of the advantages that RegTech can offer in an unexpected market crisis. The point is that deployment of Regulatory Technology has many benefits, not just in business-as-usual operating times, but also as powerful and intelligent tool to manage changing regulatory requirements in unanticipated stress events, such as the coronavirus outbreak.

\section{Conclusion}

The banking landscape has changed significantly over the last couple of decades and especially after the 2008 financial crisis. An area where significant impact was experienced for most banks is in the increase and complexity of new financial regulations and subsequent expansion of bank's compliance requirements.

The volume and complexity of bank regulations have increased significantly over the last couple of years. This has put more pressure on banks to monitor and report a range of complex exposures and comply with all the different prudential requirements.

Regulatory Technology (RegTech) has emerged as a technology trend that can assist with the regulatory obligations of banks. RegTech makes use of information technology and digital technologies for enhancing regulatory procedures such as regulatory monitoring, compliance and reporting. It has the ability to standardise, automate and speed up a lot of manual activities, which can make the process more robust and economical.

Many banks have struggled to find solutions to keep up with increasing regulation and compliance. RegTech has emerged as a lifeline to help firms ease this burden and streamline labour-intensive and costly tasks. RegTech solutions are aimed at making it easier and cheaper for financial institutions to comply with ever-changing regulations, without requiring manual processes that drive up errors, time and headcount. The problem is that digital technologies can be expensive and inefficient if deployed on a stand-alone basis. In order to achieve efficiencies, it needs to be part of an integrated deployment of digital technology firm-wide to truly add value.

This paper explored how RegTech can be incorporated into the digital transformation strategy of a bank department such as Treasury. This would mean digital solutions could be leveraged to support both strategic Treasury management activity and regulatory reporting demands. This integration will truly create a Smart Treasury function.

The combined use of digital technology for management and regulatory purposes will also strengthened the collective business case formulation for implementing these kinds of innovations within Treasury. Measurements such as return on investment will be significantly boosted if digital technology solutions are leveraged for both management and regulatory-driven purposes.

Regulatory technologies have different advantages which could all help with delivering an improved and smarter regulatory management process. However, one technology stands out, namely robotic process automation, which has relative straightforward application benefits. RPA can significantly reduce the operational and manual-intensive process of data extraction and free up Treasury personnel to focus on more strategic and subjective management activities such as interpreting the reporting output and using the information to drive commercial decisions.

Furthermore, RegTech is not just beneficial in businessas-usual times, but can also provide a flexible and powerful tool to manage changing regulatory requirements in unanticipated stress events, such as during the coronavirus outbreak.

\section{References}

1. Grundke, P., and A. Kuhn. 2020. The Impact of the Basel III Liquidity Ratios on Banks: Evidence from a Simulation Study. The Quarterly Review of Economics and Finance 75: 167-190.

2. Fidrmuc, J., and R. Lind. 2020. Macroeconomic Impact of Basel III: Evidence from a Meta-analysis. Journal of Banking \& Finance 112: 105359.

3. Boora, K.K., and Kavita. 2018. The Impact of Basel III Norms on Profitability: An Empirical Study of Indian Public Sector Banks. IUP Journal of Financial Risk Management 15 (3): 44-58.

4. Auboin, M., and I. Blengini. 2019. The Impact of Basel III on Trade Finance: The Potential Unintended Consequences of the Leverage Ratio. Journal of Banking Regulation 20 (2): 115-123.

5. Roulet, C. 2018. Basel III: Effects of Capital and Liquidity Regulations on European Bank Lending. Journal of Economics and Business 95: 26-46.

6. Basheer, M.F., M.H. Hidthiir, and W. Waemustafa. 2019. Impact of Bank Regulatory Change and Bank Specific Factors Upon Off-Balance-Sheet Activities Across Commercial Banks in South Asia. Asian Economic and Financial Review 9 (4): 419-431.

7. Alam, N., and K. Ngo. 2014. Regulatory Compliance and Cost of Banking Operation: A Survey of US Banking Sector. Journal of International Banking Law and Regulation 29 (11): 657-664.

8. Allen, M. 2014. Cost of Compliance. San Diego Business Journal 35 (36): 15.

9. Howard, C. 2014. Basel III's Corporate Governance Impact: How Increased Banking Regulations Pose Challenges to Corporate Compliance While Simultaneously Furthering Stakeholder Objectives. Journal of Business Systems Governance \& Ethics 9 (1): 39-49.

10. Financial Service Authority. Digital Regulatory Reporting: Phase 2 Viability Assessment. Digit Regul Rep. 2019;(Phase 2 Viability Assessment): 44.

11. Eyermann C. The Time Cost of Regulation. MyGovCost.org. 2017 [cited 2020 Mar 24]. Available from: http://www.mygov cost.org/2017/04/10/the-time-cost-of-regulation/.

12. Huge FK, Krieg K, Giuntini F. The RegTech universe on the rise. Deloitte Luxembourg. 2017 [cited 2020 Mar 24]. Available from: 
https://www2.deloitte.com/lu/en/pages/technology/articles/regte ch-univers-on-the-rise.html.

13. FCA. FCA 2019 fines. Financial Conduct Authority. 2019 [cited 2020 Mar 31]. Available from: https://www.fca.org.uk/news/newsstories/2019-fines.

14. Chaikovska, I. 2019. Enforcement Actions of Banking Supervision Authorities in European Union: Non-Compliance with PostCrisis Banking Regulations. International Journal of Arts \& Sciences 12 (1): 107-112.

15. Losiewicz-Dniestrzanska, E. 2015. Monitoring of Compliance Risk in the Bank. Procedia Economics and Finance 26: 800-805.

16. Podder S, Pisanu G, Ghosh B. RegTech for Regulators. World Gov Summit. 2018; Available from: https://www.worldgovernment summit.org/api/publications/document?id=5ccf8ac4-e97c-6578b2f8-ff0000a7ddb6.

17. Arner, D.W., J.N. Barberis, and R.P. Buckley. 2016. FinTech, RegTech and the Reconceptualization of Financial Regulation. Rochester, NY: Social Science Research Network.

18. Arner, D.W., J.N. Barberis, and R.P. Buckley. 2016. The Emergence of Regtech 2.0: From Know Your Customer to Know Your Data. Rochester, NY: Social Science Research Network.

19. Lynn, T., J.G. Mooney, P. Rosati, and M. Cummins (eds.). 2019. Disrupting Finance: FinTech and Strategy in the 21st Century. Cham: Springer.

20. Huge FK, Laurent P, Ramos S, Berliner L. RegTech Universe 2020. Deloitte Services; 2020 [cited 2020 Aug 14]. Available from: https://www2.deloitte.com/lu/en/pages/technology/artic les/regtech-companies-compliance.html.

21. Roszkowska, P., and L. Prorokowski. 2015. The Changing Role of a Bank's Treasury. Rochester, NY: Social Science Research Network.

22. Cadamagnani F, Harimohan R, Kumar T. A Bank Within a Bank: How a Commercial Bank's Treasury Function Affects the Interest Rates Set for Loans and Deposits. Bank of England; 2015 [cited 2020 Jun 9]. (Quarterly Bulletin 2015 Q2 article). Available from: http://www.bankofengland.co.uk/quarterly-bulletin/2015/ q2/a-bank-within-a-bank-how-a-commercial-banks-treasury-funct ion-affects-the-interest-rates-set-for

23. Elgeti C, Schäfer R, Vogt P, Broemstrup I, Lai C, Granzer M, et al. Creating a Digital Treasury in Banking. Boston Consult Group. 2019.

24. Hawser, A. 2019. Dawn Of The "Super Treasurer": Artificial Intelligence is Moving from the Consumer to the Business Sector, Turning the Treasury Function into a Sophisticated Analytic Center. Global Finance 33 (8): 33-34.

25. Polak, P., C. Nelischer, H. Guo, and D.C. Robertson. 2020. "Intelligent" Finance and Treasury Management: What We Can Expect. AI and Society 35: 1-12. (Preprints).

26. Von Solms J, Langerman J. A Smart Treasury fit for the 4th Industrial Revolution. In: FEMIB 2020 [Internet]. 2020. Available from: https://www.insticc.org/node/TechnicalProgram/femib /2020/personDetails/00e65df0-5615-4a51-809b-60a49ef97d3f.

27. Finch G. World's Biggest Banks Fined \$321 Billion Since Financial Crisis. Bloomberg. 2017 [cited 2020 Mar 31]. Available from: https://www.bloomberg.com/news/articles/2017-03-02/world -s-biggest-banks-fined-321-billion-since-financial-crisis.

28. Business Insider. Thomson Reuters Launches a RegTech Solution. Business Insider. 2017 [cited 2020 Mar 31]. Available from: https ://www.businessinsider.com/thomson-reuters-launches-a-regtechsolution-2017-1? $\mathrm{r}=\mathrm{US} \& \mathrm{IR}=\mathrm{T}$

29. Spain Today. Banks' AI Plans Pose Threat in Order to Thousands of Jobs. SpainToday.es. 2017 [cited 2020 Mar 31]. Available from: https://spaintoday.es/uncategorized/banks-ai-plans-pose-threat-tothousands-of-jobs/.

30. Banerjee R, Mio H. The Impact of Liquidity Regulation on Banks. BOE Staff Work Pap No 536. 2015; Available from: https://www. bankofengland.co.uk/-/media/boe/files/working-paper/2015/theimpact-of-liquidity-regulation-on-banks.pdf.

31. Lindblom, T., S. Sjögren, and M. Willesson. 2014. Challenges for Banks and a New Regulatory Framework. In Governance, Regulation and Bank Stability, ed. T. Lindblom, S. Sjögren, and M. Willesson. London: Palgrave Macmillan UK. https://doi. org/10.1057/9781137413543_1.

32. Larsen, K., and S. Gilani. 2017. RegTech is the New Black-The Growth of RegTech Demand and Investment. Journal of Financial Transformation 45: 22-29.

33. Deloitte. Banking Regulatory Outlook. Deloitte United States. 2020 [cited 2020 Mar 31]. Available from: https://www2.deloi tte.com/us/en/pages/regulatory/articles/banking-regulatory-outlo ok.html.

34. Association of Finance Professionals. 2017 AFP Strategic Role of Treasury Survey. Association of Finance Professional; 2017 [cited 2020 May 28]. Available from: https://www.oliverwyman.com/ our-expertise/insights/2017/may/2017-afp-strategic-role-of-treas ury-survey.html.

35. Lipton A, Shrier D, Pentland A. Digital Banking Manifesto: The End of Banks? Mass Inst Technol. 2016; Frontiers in Financial Technology: Future of Commerce: 19.

36. Polak, P., F. Masquelier, and G. Michalski. 2018. Towards Treasury 4.0/The Evolving Role of Corporate Treasury Management for 2020. Management - Journal of Contemporary Management Issues 23: 189-197.

37. European Commission. Public consultation on fitness check on supervisory reporting. European Commission; 2018 [cited 2020 Aug 14]. Available from: https://ec.europa.eu/info/consultations/ finance-2017-supervisory-reporting-requirements_en.

38. BBVA. 10 keys to understand what regtech is all about I BBVA. NEWS BBVA. 2016 [cited 2020 Aug 12]. Available from: https ://www.bbva.com/en/10-keys-understand-regtech/.

39. Johansson, E., K. Sutinen, J. Lassila, V. Lang, M. Martikainen, and O.M. Lehner. 2019. Regtech- A Necessary Tool to Keep Up With Compliance and Regulatory Changes? ACRN Journal of Finance and Risk Perspectives, Special Issue Digital Accounting 8: 71-85.

40. Arner, D.W., J.N. Barberis, and R.P. Buckley. 2017. FinTech and RegTech in a Nutshell, and the Future in a Sandbox. CFA Institute 3 (4): 1-20. Foundation Briefs.

41. Anagnostopoulos, I. 2018. Fintech and RegTech: Impact on Regulators and Banks. Journal of Economics and Business 100: 7-25.

42. Copinni I. 'RegTech is the New FinTech'. Deloitte Services; 2016 [cited 2020 Aug 12]. Available from: https://www2.deloitte.com/ $\mathrm{mt} / \mathrm{en} / \mathrm{pages} /$ financial-services/articles/mt-regtech-is-the-newfintech.html.

43. Skilton, M., and F. Hovsepian. 2017. The 4th Industrial Revolution: Responding to the Impact of Artificial Intelligence on Business. Cham: Palgrave Macmillan.

44. Harvey, D. 2016. Digital Transformation in Banks: The Trials, Opportunities and a Guide to What is Important. Journal of Digital Banking 1 (2): 136-145.

45. FCA2. Money Laundering Regulations. Financial Conduct Authority. 2020 [cited 2020 Apr 6]. Available from: https://www. fca.org.uk/firms/financial-crime/money-laundering-regulations.

46. Grant Thornton. Is RegTech the Future of Compliance. Grant Thornton. 2019 [cited 2020 Mar 31]. Available from: https://www. grantthornton.com/library/articles/financial-services/2018/BK/ RegTech-future-compliance.aspx.

47. Hewlett, R. 2010. Treasury Value Creation: Integrating Strategic Planning, Capital Budgeting, Enterprise Risk Management, and Liquidity. Journal of Corporate Treasury Management 4 (2): 14.

48. Phillips, A.L. 1997. Treasury Management: Job Responsibilities, Curricular Development, and Research Opportunities. Financial Management 26 (3): 69-81. 
49. Maphiri, D. 2001. Treasury's Role in Promoting Efficient Cash Management: Evidence from South Africa. South African Journal of Economics 69 (3): 385-404.

50. van Rooyen, J., and W. Reitsma. 2004. The Future Effect of E-Business on Treasury and Risk Management Systems and Treasury Management in South Africa. Development Southern Africa 21 (2): 399-414.

51. Helliar, C., and T. Dunne. 2004. Control of the treasury function. Corp Gov Int J Eff Board Perform 4 (2): 34-43.

52. San Jose, L., T. Iturralde, and A. Maseda. 2008. Treasury Management versus Cash Management. International Research Journal of Finance and Economics 19: 192-204.

53. Polak, P. 2010. Centralization of Treasury Management in a Globalized World. Rochester, NY: Social Science Research Network.

54. Bragg, S. 2010. Treasury Management: The Practitioner's Guide. Hoboken, N.J.: Wiley.

55. Koh B. Strategic Treasury: What Does it Involve?. The Global Treasurer. 2016 [cited 2020 May 27]. Available from: https:// www.theglobaltreasurer.com/2016/05/26/strategic-treasury-whatdoes-it-involve/.

56. Meall L. Why Treasury must automate to survive the pandemic. Association of Corporate Treasurers. www.treasurers.org/hub/ treasurermagazine/why-treasuries-must-automate-to-survivepandemic.

57. BCBS. History of the Basel Committee. Bank of International Settlement. 2014 [cited 2020 Apr 6]. Available from: https://www. bis.org/bcbs/history.htm.

58. Basel, (ed.). 2013. Basel III: The Liquidity Coverage Ratio and Liquidity Risk Monitoring Tools, vol. 2012, 69. Basel: Bank for Internat Settlements.

59. Basel, S. (ed.). 2014. Basel III Leverage Ratio Framework and Disclosure Requirements, vol. 2014, 19. Basel: Bank for International Settlements.

60. BOE1. Regulatory Reports for Banks, Building Societies and Investment Firms. Bank of England. 2020 [cited 2020 Mar 31]. Available from: http://www.bankofengland.co.uk/prudential-regul ation/regulatory-reporting/regulatory-reporting-banking-sector/ banks-building-societies-and-investment-firms.

61. PRA. PRA Fines Citigroup’s UK Operations $£ 44$ Million for Failings in Their Regulatory Reporting Governance and Controls.
Bank of England. 2019 [cited 2020 Mar 31]. Available from: http://www.bankofengland.co.uk/news/2019/november/pra-fines -citigroups-uk-operations-44-million-for-failings.

62. AFP. 2018 AFP Risk Survey Report. Association of Finance Professional; 2018 [cited 2020 May 27]. (Treasury Risk Survey Report). Available from: https://www.oliverwyman.com/ourexpertise/insights/2018/jan/2018-afp-risk-survey-report.html.

63. Von Solms J. (2020) Digital Technology adoption in a bank Treasury and performing a Digital Maturity Assessment.

64. Dolente J, Schmachtenberg F, Zeller M, Bachmann J. Dawn of a New Partnership - A Robotics Led Finance Function. Ernst and Young. 2017 [cited 2020 Mar 25]. Available from: https://www. eycom.ch/en/Publications/20171101-The-dawn-of-a-new-partn ership/download.

65. SARB. Prudential Authority Offers Relief Measures, Guidance to South African Banks Amid COVID-19 Crisis. CNBC Africa. 2020 [cited 2020 Apr 13]. Available from: https://www.cnbcafrica .com/news/2020/04/07/prudential-authority-offers-relief-measu res-guidance-to-south-african-banks-amid-covid-19-crisis/.

66. BOE2. Statement on VAR Back-Testing Exceptions Temporary Approach. Bank of England. 2020 [cited 2020 Apr 13]. Available from: http://www.bankofengland.co.uk/prudential-regulation /publication/2020/var-back-testing-exceptions-temporary-appro ach.

Publisher's Note Springer Nature remains neutral with regard to jurisdictional claims in published maps and institutional affiliations.

Johan von Solms The author has over 20 years of experience in the regional and global financial markets, across a diverse range of banking and Treasury disciplines including: funding and liquidity risk management; debt capital market issuance; sales and trading; and financial regulations. He is also studying for $\mathrm{a} \mathrm{PhD}$ on the digitalisation of internal bank management functions such as Treasury and finance. 